\title{
ANÁLISE DISCURSIVA DAS REPRESENTAÇÕES DA(S) MASCULINIDADE(S) EM EDITORAIS DA MEN'S HEALTH
}

\author{
NOTES OF A DISCURSIVE ANALYSIS OF REPRESENTATIONS OF \\ MASCULINITY(S) IN PUBLISHERS OF MEN'S HEALTH
}

\author{
Recebido: 06/11/2020 Aprovado: 04/01/2021 Publicado: 10/01/2021
}

DOI: $10.18817 /$ rlj.v4i02.2391

\author{
Ederson Luís da Silveira ${ }^{1}$ \\ Orcid id: http://orcid.org/0000-0002-8483-4656 \\ Lucas Rodrigues Lopes ${ }^{2}$ \\ Orcid id: http://orcid.org/0000-0002-9936-3666
}

Resumo: O conceito de masculinidade pode ser uma peça fundamental para pensar acerca da regulação de corpos na contemporaneidade, uma vez que, na maioria das pesquisas que o operacionalizam, seu uso não é reificador nem essencialista. O presente texto parte da análise de recortes discursivos de dois editoriais da revista Men's Health para buscar notar como as redes de discursivização estão associadas a modos de enunciar acerca da produção da masculinidade. Conclui-se que a masculinidade é da ordem da produção e que, ao reafirmar modos de existência da masculinidade, ocorre a subalternização de outras formas de (re) existência. Desse modo, se torna urgente pensar nas representações e práticas discursivas que refletem no modo como se dá a regulação de corpos na contemporaneidade. A teoria que embasou as análises foi a análise de discurso francesa de Michel Pêcheux.

Palavras-chave: Discurso. Masculinidades. Produção de gênero.

Abstract: The concept of masculinity can be a fundamental part of thinking about the regulation of bodies in contemporaneity, since, in most studies that operationalize it, its use is neither reifying nor essentialist. This paper is part of the analysis of discursive clippings of two editorials of Men's Health magazine to try to notice how discursivization networks are associated with ways of enunciating about the production of masculinity. It is concluded that masculinity is of the order of production and that, by reaffirming modes of existence of masculinity, there is the subalternization of other forms of (re) existence. Thus, it becomes urgent to think about the representations and discursive practices that reflect on the way bodies are regulated in contemporary times. The theory that supported the analyses was the analysis of French discourse by Michel Pêcheux.

Keywords: Discourse; Masculinities; Gender production.

\section{Introduzindo o percurso}

\footnotetext{
${ }^{1}$ Doutor e Mestre em Linguística pela Universidade Federal de Santa Catarina (UFSC); Membro-Pesquisador dos Grupos de Pesquisa Michel Foucault e os Estudos Discursivos (UFAM/CNPq) e Formação de Professores em Línguas e Literatura (FORPROLL/CNPq).E-mail: ediliteratus@gmail.com

2 Professor adjunto da Universidade Federal do Pará (UFPA); Doutor em Linguística Aplicada pela Unicamp; Mestre em Linguística pela UFSCAR; Membro-Pesquisador do Grupo de Pesquisa Estudos do Discurso, Sentido, Sociedade e Linguagem (DISENSOL - UFPA/CNPq). E-mail: identidadesfragmentadas@gmail.com
} 
Em 2018, o dicionário Oxford elegeu o termo "tóxico" como palavra do ano. A Segunda palavra foi "masculinidade". Em terceiro lugar ficaram as duas juntas classificadas como expressão do ano: "masculinidade tóxica". Anualmente a publicação eletrônica elege palavras ou expressões que atraem maior interesse nas buscas pela internet. Na ocasião, a pesquisa pelo termo "tóxico" associado a "masculino" foi efetuada tantas vezes que a plataforma considerou a existência de um aumento de $45 \%$ de vezes no site oxforddictionaries.com. O evento histórico que pode ter alavancado as buscas pelo termo foi a instauração do movimento \#MeToo, por meio do qual houve estímulo à revelações acerca de abusos sexuais em instâncias virtuais de compartilhamento e visualização mundial. Mais do que revelar comportamentos que adoecem e subalternizam sujeitos, é sobre machismo que estamos nos referindo. Sobre machismo, valem as palavras de Mirian Béccheri Cortez, psicóloga judiciária no Tribunal de Justiça de São Paulo (TJ-SP), que trabalha com casos de violência de gênero e estudou o tema em seu doutorado:

\begin{abstract}
Quando me refiro a machismo, entendo esse termo como um conjunto de atitudes, práticas e valores tradicionalistas, sexistas e misóginos, que se criou e se estabeleceu como uma de nossas bases culturais em decorrência de nossa base histórica patriarcal. Esse conjunto conduz comportamentos e expectativas em nosso dia-a-dia - de homens e mulheres. O machismo traz prejuízos individuais e sociais para a mulher (assédios, menosprezo do feminino, violências em relacionamentos afetivos e outras relações sociais), e impacta negativamente também o homem e esse fato precisa ser falado e compreendido nos mais diversos espaços (CORTEZ, 2019, s. p.).
\end{abstract}

Não é exagero afirmar que o machismo está associado à produção de masculinidades no decorrer da história. Também é necessário mencionar que o conceito de masculinidade foi sendo reformulado com o passar do tempo no campo das Ciências Humanas. Raewyn Connell (1995) é um pensador da área que cunhou outro termo - masculinidade hegemônica - para pensar também na proliferação de masculinidades que são reguladas por um eixo norteador excludente. Trata-se de pensar em como as categorias homem, gênero e hierarquia social são passíveis de análise, sobretudo devido ao fato de estarem inter-relacionadas.

Não é à toa que Silveira (2015), ao mencionar as contribuições de Judith Butler para os estudos de gênero, afirma que os direitos sexuais, o olhar para a diversidade e a multiplicidade de identidades sexuais existentes direcionam-se em oposição às normas e regulações sociais que visam instituir o gênero enquanto 
categoria homogeneizada por meio do discurso. Isso porque, por meio do estudo das análises históricas da sexualidade que Foucault empreendeu, Butler obteve parte do embasamento para a formulação de que gênero, sexo e sexualidade não podem ser vistos como entidades fixas, mas construídas e reconstruídas ao longo dos anos em diferentes sociedades e contextos (Cf. SILVEIRA \& BASTISTA, 2019). Isso permite afirmar que estamos no terreno da desnaturalização de formulações impostas e de desconfianças acerca de objetos do discurso que são colocados no lugar do verdadeiro.

Para além da masculinidade hegemônica, há, também, uma masculinidade subalternizada, caracterizada de forma depreciativa, como a de homens que estão desprovidos do seu poder simbólico de provedores (BOURDIEU, 1989, 1999; CARNEIRO, 1999; CONNELL \& MESSERSHMIDT, 2013; GOLDENBERG, 1991; KIMMEL, 1998). Para Silveira (2015) a produção da subjetividade - e do gênero não é fixa, imutável e homogênea. Segundo o autor mencionado, cuidados e representações do corpo estão associados a regulações, a uma exterioridade constitutiva e, também, podem fazer insurgir modos de resistência. Outrossim, é comum que revistas ou matérias que falem sobre masculinidade se voltem para a repetição de atos que produzem gêneros de modo a associar um modo de ser homem (heterossexual) a uma hierarquia em relação a outras formas de existência.

Dessa forma, havendo uma que seja hegemônica, as demais ficam subalternizadas, execradas, relegadas à margem. Desse modo, para Connell e Messerschmidt (2013), o conceito de masculinidade pode ser uma peça fundamental para pensar acerca da regulação de corpos na contemporaneidade, uma vez que, na maioria das pesquisas que o operacionalizam, seu uso não é reificador nem essencialista. Nesse contexto, o site da Revista Men's Health (https://menshealth.pt/) é um dos veículos de informação que atua na manutenção desse tipo de masculinidade, o que permite a tessitura de algumas considerações pertinentes à análise discursiva que apresentamos posteriormente a fim de averiguar como isso ocorre.

Vale destacar que, nesse âmbito de considerações, a (re) produção de discursos está envolva na reificação de práticas e representações sobre inúmeros temas que são tomados como objetos de discurso; nesse caso, acerca da masculinidade, por exemplo. Vale destacar que o estrato da revista norte-americana é mensal e direciona as publicações de vários países. No escopo do periódico, 
vemos algumas marcações relevantes à ordem do discurso emergente nas representações da masculinidade, já que se define como "a maior revista do gênero para homens". Nesse sentido, no âmbito do espectro de estudos pecheutianos (cf. PÊCHEUX, 1997, p. 77), vemos os sujeitos - aos quais se atribuem tipos específicos de masculinidades - nos editoriais serem atravessados por instâncias discursivas, que apontam para um contexto imediato, atrelando-os às condições de enunciação sócio-histórico-ideologicamente singulares. Esse olhar pode ser capturado nos dizeres da própria revista, quando se apresentam como a maior revista do gênero para homens, com 38 edições em todo o mundo, em tiragem mensal de 1,85 milhões de leitores mensais, tendo um conteúdo que visa abranger o homem moderno em "todos os aspectos": fitness, nutrição, sexualidade, saúde e estilo de vida.

Assim, significativo à análise discursiva proposta é o modo de funcionamento discursivo, que constitui as representações do leitor desse veículo de comunicação. No site da Men's Health, por exemplo, por meio da dicotomia "O prazer de ser homem" X "Viver melhor é fácil" torna-se profícuo refletir sobre o sintagma nominal "O prazer+ de + ser homem", já que existe uma representação do que é ser homem na sociedade atual, bem como vale ressaltar os efeitos de sentido em torno dessa construção. O vocábulo "prazer" produz um efeito de sentido de sensação/emoção, de satisfação de uma vontade, além de ser pertinente arrolar que, se a revista categoriza-se como meio de comunicação, tramitando entre "O prazer de ser homem" X "Viver melhor é fácil”, vemos emergir a representação do homem como uma satisfação de uma vontade, de uma necessidade a ser alimentada. Também acerca do vocábulo "homem" é importante mencionar que há um reforço de estereótipos acerca da masculinidade como se esta pudesse ser atribuída a um bloco monolítico dado de antemão. A revista se apresenta como um veículo de informação, sobretudo, para homens heterossexuais.

\section{Gestualidades teórico-descritivo-interpretativas sobre o corpus}

Vale considerar que as práticas discursivas estão associadas a determinadas práticas sociais e apontam para uma inscrição que é histórica, cultural e ideologicamente orientada, associadas a um recorte da vida social por meio de um direcionamento específico. Nessa visão, consideramos os estudos de Louro (2000, 
p. 13), que discutem que "podemos entender que a sexualidade envolve rituais, linguagens, fantasias, símbolos, convenções. São processos profundamente culturais e plurais". Disso depreendemos que os corpos passam por transformações históricas, ganhando sentido socialmente. Ademais, é oportuno discutir o vínculo ao gênero que é sempre um olhar contextual e cultural, isto é, precisamos vislumbrar as marcas dessa cultura no modo em que expressam discursivamente desejos e prazeres, bem como fazem compor e definem identidades de gênero e sexuais por meio das relações de poder emergentes numa dada sociedade. Para isso, atentemos aos discursos que atravessam as representações de quem se filia e é filiado ao meio de comunicação em questão. Os recortes discursivos foram extraídos das edições da Men's Health de maio de 2013, número 85 e da Men's Health de abril de 2018, número $201^{3}$. Considerando dois textos da Carta do Editor da Men's Health, cuja responsabilidade é de Artur Seligman, como corpus de análise, temos:

\section{Recorte Discursivo 1 (RD1)}

"Ao celebrarmos 7 anos, fizemos uma edição de aniversário exatamente com a sua cara. Ou melhor, com a cara que você vai ter"

Com Orlandi (2005, p.59), compreendemos que "quando lemos, estamos produzindo sentidos (reproduzindo-os ou transformando-os). Mais do que isso, quando estamos lendo, estamos participando do processo (sócio-histórico) de produção de sentidos". Sendo assim, refletindo sobre o modo de representação dos leitores da Men's Health com base no RD1, podemos considerar que os dizeres "fizemos uma edição exatamente com a sua cara" traz efeitos de sentido de que o leitor tem o poder de moldar as edições publicadas pela revista, isso pode ser materializado pelo uso do advérbio "exatamente", cujo emprego instaura a emergência de vocábulos, tais, como, por exemplo: "com rigor", "com exatidão", "nem mais, nem menos", "precisamente".

Entretanto, os dizeres "com a cara que você vai ter" descontroem esse mesmo poder de ação, advindo das atitudes masculinas; é como se a dominação masculina fosse momentaneamente tirada de cena e dissessem que o ser homem dependesse de uma alcunha, que só a filiação às normas e orientações expressas na Men's Health o autorizassem para isso. Ocorre, então, um efeito de legitimação

\footnotetext{
${ }^{3}$ Ambas as edições podem ser acessadas no site https://menshealth.pt/estatuto-editorial/
} 
de um lugar de poder associado ao exercício de um tipo de masculinidade que é reforçado pelas premissas do periódico. Esse efeito de sentido pode ser capturado pelos dizeres "com a cara que você vai ter", isto é, a partir do substantivo "cara", temos o efeito de sentido atrelado à "feição", "aparência" e "fisionomia" masculina, já que a publicação visa o ensino de comportamentos e regras do que é ser homem. Além dessa acepção, vale salientar que a própria palavra "cara" também pode ser vocativo e se referir à "indivíduo", "pessoa" e "sujeito", um olhar semântico para a própria constituição da masculinidade, uma vez que cria um certo tipo de chamamento entre os "parceiros e machos".

É importante mencionar que, em tal RD, a masculinidade considerada não é qualquer uma: trata-se de um efeito de produção de essencialismos, no qual cabem determinados comportamentos enquanto outros são rechaçados, como o de homens que não se adequam ao estereótipo do "macho" e "viril". Assim, o jogo de palavras "a sua cara - a cara que você vai ter" coloca o leitor homem heterossexual como produto de uma discursivização performática acerca de um tipo de comportamento, que remete a uma regulação de corpos e condutas, viabilizada por meio da identificação com a formação ideológica da virilidade somada à concordância da necessidade de "melhorar" para ficar "ainda melhor". Desse modo, podemos concluir que há uma contradição fundante do enunciado: ao mesmo tempo em que se apregoa que a revista está "a cara" de quem lê ela também impera que a masculinidade não é da ordem do acabamento, mas da produção, ela não cessa de se reinscrever na história e, por isso, precisa ser "adestrada". Tal adestramento de corpos não ocorre sem uma série de exclusões sobre como os corpos não devem se portar, por exemplo. Daí se percebe que não se trata de apenas recomendações, formulações, ordenamentos e preceitos acerca da masculinidade, mas de cerceamentos e exclusões que produzem o efeito de subalternizar outros modos de manifestação do gênero e da sexualidade.

\section{Recorte Discursivo 2 (RD2)}

Um cara como você comprou o número de uma revista masculina diferente de completamente tudo que havia no mercado: homem na capa, conteúdo de bem-estar, jornalismo de serviço, ou seja, ousadia muito além do entretenimento. Enfim, você entende se tratar de um verdadeiro manual para viver melhor. Um futuro legal ao alcance das mãos. 
Considerando os estudos propostos por Meyer (2004), definimos gênero com base em uma noção cultural acerca da produção de masculino e feminino, sendo um sistema de significação por meio do qual são orientadas as formas de vivermos as masculinidades e feminilidades, por meio da linguagem, organizando, assim, a vida social. Nesse sentido, Scott (1995, p. 86) discorre sobre essa faceta por destacar que a noção de gênero é também uma "forma primária de dar significado às relações de poder", tendo sido, ao longo dos anos, um constituinte de inúmeros processos de desigualdade social.

Em se tratando do RD2, vemos funcionar o que Orlandi (2000, p. 11) destaca quando afirma que "[a]s palavras não são só nossas. Elas significam pela história e pela língua. O que é dito em outro lugar também significa nas 'nossas' palavras". Isso pode ser materializado linguisticamente pelo modo como o "cara" é representado. Em primeira instância, ele é visto como pertencente à "aura" masculina, pois se inscreve na ordem discursiva do consumo. Ele precisa comprar para ser, há determinadas informações que a revista oferece e que só ela oferece no sentido de ser "diferente das demais".

Dessa forma, a revista exerce um olhar coercitivo sobre o consumidor, já que as edições o fazem ter acesso ao "número de uma revista masculina diferente de completamente tudo que havia no mercado", o homem estampando a capa afeiçoa e apresenta similitudes, "o conteúdo de bem-estar" produz um efeito de notoriedade, a revista adquire caráter de guia de instruções que o sujeito precisa seguir para ser o "cara masculino". Interessante notar como a revista joga com a singularidade discursiva, uma vez que pinça nas palavras uma unicidade, que pode ser vislumbrada por "Um cara como você comprou um número de uma revista masculina diferente", como se o sujeito fosse consumido e consumisse a masculinidade em vitrine. Produz, também, um efeito de singularização daquele que lê: ele é semelhante a outros homens, mas também é singular no que diz respeito à escolha de adquirir o periódico: a sedução da publicidade caracteriza os prováveis adquiridores do produto em relação aos demais, que são "menos informados" acerca da produção da masculinidade, que é tomada como objeto de discurso via enunciado e colocada no lugar do verdadeiro, como se não houvesse outras produções de masculinidade e aquela que a revista apresenta fosse "a legítima", "indiscutivelmente" a mais "adequada" para quem quiser saber como exercer a masculinidade de modo "eficaz". 


\section{Recorte Discursivo 3 (RD3)}

Mesmo quando você celebra o passado, como estamos fazendo nesta edição, desde o começo, sempre olhamos para frente. É isso que faz você, leitor, e a $\mathrm{MH}$ formarem uma parceria afinadaça.

A ideologia é um elemento que determina sentidos, constituindo a prática discursiva ao mesmo tempo em que se reflete na exterioridade. Interessante apontar como a noção de ideologia orienta os sentidos emergentes nos/dos enunciados. Isso porque é entendida como efeito da relação entre sujeito e linguagem, não sendo consciente, mas estando presente em toda manifestação do sujeito. Para Leandro Ferreira (2001, p. 17) "[t]anto a crença do sujeito de que possui o domínio de seu discurso quanto a ilusão de que o sentido já existe como tal são efeitos ideológicos". Neste caso, no RD3, o conceito de ideologia se faz presente em qualquer manifestação discursiva, fator que permite ao analista do discurso tracejar que formações discursivas são dominantes. Em se tratando da questão da masculinidade e do pertencimento ao universo de assinantes da Men's Health, vemos uma representação nos dizeres "Mesmo quando você celebra o passado", que aponta para um exercício e esforço, talvez uma transposição ao longo do tempo, para transparecer jovialidade e virilidade.

Desse modo, concebemos a formação discursiva "como aquilo que numa formação ideológica dada, ou seja, a partir de uma posição dada em uma conjuntura sócio-histórica determina o que pode e deve ser dito" (ORLANDI, 2001, p.43). Ainda, em referência ao RD3, vemos como a sexualidade, um dispositivo histórico, como afirma Foucault (1988), em outras palavras, é uma invenção social, constituída, historicamente, com base em discursos outros que regulam, visam normatizar, instaurar saberes, sobretudo, produzem verdades.

Vemos essa faceta entrar em funcionamento, quando o editor faz um jogo assimétrico por assim dizer "desde o começo, sempre olhamos para frente" $X$ "É isso que faz você, leitor, e Men's Health formarem uma parceria afinadaça". Trazemos à reflexão o uso do marcador temporal "desde o começo", que instaura a preocupação com quem é assinante do estabelecimento e fortalecimento de uma regularidade, sem contradições (sic), e segue o Manual Men's Health, já que ser homem viril, masculino e com protocolos de cuidado físico faz com que "sempre olhamos para frente". Dentro dessa perspectiva, vemos a noção de sexualidade à margem, pois há discursos que atravessam o leitor. 
A contradição que constitui o enunciado é da ordem das condições de enunciabilidade: aqueles tipos de sexualidade que não são regularizadas, reafirmadas, reproduzidas no decorrer do tempo "escapam" a seriedade que a revista busca apregoar e defender como legítima. Esse efeito de legitimidade traz outro efeito: o de que a produção de gêneros é um processo que nunca termina, que não cessa de se reinscrever na história, por isso a alusão a um passado que precisa ser preservado no olhar para o futuro já que há homens que "não olham para o futuro" ao não preservar e reafirmar modos de exercício da masculinidade que são específicos e reiterados. Por fim, há um recorte e um direcionamento específicos: aquele que segue as diretrizes impostas e materializadas nos discursos apresentados pode usufruir de uma "parceria afinadaça". Chama nossa atenção o esforço linguístico para compor um linguajar que torne o pertencimento ao mundo da masculinidade uma possibilidade por meio do uso da informalidade. Assim, ao mesmo tempo em que se (re) afirma que a masculinidade é da ordem do repetível, também se produz o efeito de subalternização de outros tipos de exercício da masculinidade.

\section{Recorte Discursivo 4 (RD4)}

Ei, essa é só a parte hardcore da nossa missão, por assim dizer - mexer de forma visceral no seu estilo de vida, fazê-lo abraçar um jeito de existir ao mesmo tempo leve e sofisticado, com mais foco, e por isso com mais diversão também. A outra parte, o lado rock and roll (mas não menos científico) de nossa existência é dar soluções rápidas, práticas, que têm apelo e resultado imediato: o que vestir para uma reunião com o chefe, como conduzir um papo sedução, como tratar uma frieira do pé, que treino fazer para trincar em um mês.

Nesse RD4, chama nossa atenção a construção do ser dotado de masculinidade como exercício de obediência, como se existisse um caminho a ser transposto. Inclusive, apontamos alguns atravessamentos do discurso religioso. Vemos isso por meio da ocorrência de palavras do campo semântico da figura do homem religioso "essa é só parte hardcore da missão". O uso da palavra "missão" traz o efeito de sentido de incumbência que alguém deve executar a pedido ou por ordem de outrem, como se a mudança fosse um encargo.

É também parte desse exercício de obediência deixar-se ser mexido nas vísceras, uma vez que o homem de verdade é aquele que deixa "mexer de forma visceral em seu estilo de vida". Interessante destacar que a construção "de forma visceral" faz emergir um efeito de sentido que ronda aquilo que se encontra arraigado, muito íntimo ou profundo. Nesse sentido, ainda, podemos refletir como a 
noção de gênero também carrega uma origem discursiva do sexo (BUTLER, 2003). Isso pode ser pensado no modo como as representações culturais também podem surgir como uma forma de constituir as representações culturais de sexualidade. Em outras palavras, com base no RD4, o leitor até pode ter uma "missão hardcore", que tramita entre ser "leve", "sofisticado" e "ter mais foco", mas precisa ter um lado representado por um indicador da masculinidade - o lado rock and roll, que é pinçado pelos dizeres "dar soluções rápidas, práticas, que têm apelo e resultado imediato: o que vestir para uma reunião com o chefe, como conduzir um papo sedução, como tratar uma frieira do pé, que treino fazer para trincar em um mês", dizeres esses que instauram um sistema simbólico que depende da regulação e da normatização de práticas de generificação específicas para poder se afirmar.

Também a masculinidade está associada à ordem do engajamento e da condução: por isso os verbos na ordem do imperativo - o que vestir, como conduzir, que treino fazer - que são colocados num lugar de legitimação, referentes a ações que não podem ser negligenciadas para que se alcance um modelo ideal de masculinidade: dupla caracterização se opera novamente sobre os que cumprem os tais requisitos e os que agem de modo diferente, produzindo-se, também, um efeito de hierarquização de um tipo de masculinidade sobre as demais.

\section{Recorte Discursivo 5 (RD5)}

Para dar um up no seu astral, aqui está o nosso Guia de Estilo de Inverno (pág. 88) com 124 soluções para montar um look imbatível. Além de grandes cervejas para curtir legal este outono/inverno (pág. 117). Mais adiante, há uma sacada esperta sobre sustentabilidade (pág. 132) que vai fazer você pensar na defesa do meio ambiente muito além dos ecochatos. Nesta edição, você ainda encontra soluções para o seu dia a dia (quer um quarto melhor no hotel?) tão simples que vai perguntar "como não pensei nisso antes?" (pág. 82) E jamais vai amarelar se encontrar uma mulher poderosa pela frente (pág. 108). Também ganha treinos mastigados, fáceis, práticos - não importa a desculpa, seja falta de tempo ou espaço, você não tem escapatória para botar o corpo em forma (pág.76). O mais legal é que, embarcando nesses dois caminhos - o de resetar o chip interno e de turbinar o que manda para fora - sua vida vai vibrar ao som de um rock mais divertido e desafiador, com uma pegada de prazer e energia jamais sentida.

Há emergências em torno da representação do que é ser homem e pertencer ao hall de assinantes da Men's Health. Em primeira instância, vemos que a masculinidade também faz funcionar um tipo de homem moderno, que se cuida e segue protocolos a fim de "montar um look imbatível". Vislumbramos que a bebida, 
neste caso a cerveja, marca uma faceta do que é ser masculino e produz um efeito de afirmação da sexualidade e da generificação de comportamentos tidos como culturalmente "apropriados".

Além disso, por meio desse trecho do editorial veiculado, vemos funcionar uma estratégia discursiva que ora filia ora faz (re) filiar o leitor ao discurso da sustentabilidade, mas o torna distinto dos "ecochatos". Dessa forma, ainda que se coloque a defesa do meio ambiente como pauta é o modo de dizer que vai "tirar as frescuras" que a associam a pessoas consideradas "chatas" por causa de seu discurso: se trata de enfocar na questão de como dizer a fim de mostrar a importância da pauta, o que coloca outros modos de dizer sobre a sustentabilidade no campo do (in) dizível, de outro modo, a fim de angariar filiações discursivas e adeptos. Nesse sentido, o corpo ainda ganha destaque, pois coercitivamente leva o leitor a funcionar como um robô que escolhe "resetar o chip interno e de turbinar o que manda para fora", novamente instaurando um olhar do prazer de ser homem "com uma pegada do prazer e energia jamais sentida".

A questão da conquista é mostrada por meio do estabelecimento de uma exclusão constitutiva: a revista está direcionada a homens heterossexuais que sentem atração por mulheres. Por isso, a revista se direciona ao homem que "jamais vai amarelar se encontrar uma mulher poderosa pela frente". O adjetivo "poderosa" qualifica o que é da ordem do inacessível, do quase intangível e instaura uma identificação com aqueles que buscam dominar o outro no sentido de encontrar formas de "caçar" mulheres consideradas culturalmente difíceis - geralmente mulheres independentes e bem sucedidas ou mesmo de corpos esculturais.

Aí também se produz uma dupla subalternização: dos homens que não sentem atração por mulheres e das mulheres que não são poderosas e, portanto, fáceis. Para o último grupo, não seriam necessárias dicas de conquista, e, ao apresentar "fórmulas" para paquerar, a revista também caracteriza os homens que "não conseguem" oferecendo a eles a sedução publicitária de um lugar que podem vir a ocupar. Assim, os comportamentos associados a um exercício "coerente" e "legítimo" da masculinidade são apresentados como sendo possíveis e a revista emerge como aquela que disponibiliza ferramentas para alcançar um lugar de produção de gênero que resulta em modos de generificação específicos.

\section{Considerações finais}


No presente texto buscamos analisar como ocorrem os processos de (re) produção de masculinidades a partir da análise de dois editoriais da revista Men's Health. Percebemos que normas e regulações culturais funcionam com base em mecanismos discursivos, que constantemente são reforçados. A partir dos estudos propostos por Louro (2004), podemos mencionar que as diversas práticas sociais, como rituais em torno da modificação corporal ou mesmo rotinas adotadas têm servido para naturalizar regimes de regulação sobre o Outro. Discursivamente, podemos mencionar que inúmeros sentidos vão sendo construídos e fixados no decorrer da história da humanidade sobre modos de generificação dos corpos e, assim como são produzidos, podem ser desmantelados e desnaturalizados por meio de gestos descritivo-interpretativos.

Também observamos que existem práticas que visam à representação da masculinidade na sociedade contemporânea, privilegiando determinados modos de exercício da masculinidade enquanto ocorre a subalternização de outras formas de manifestação que escapam a tais rotulações. Diante disso, é importante reafirmar que a produção de masculinidades não é um bloco monolítico fechado e acabado, é da ordem da produção e, por isso, tem aparição em sociedade como algo que precisa ser "revelado", reiterado, contestado, problematizado. Se é da ordem da produção e nunca está pronto, então é aí, justamente onde pode ser notado o exercício do poder, que pode haver resistência. Isso porque desnaturalizar e conhecer os modos de exercício do poder e da regulação de corpos são atos que fazem parte da insurreição e defesa de outras formas de existência.

\section{Referências}

CORTEZ, Mirian Béccheri. O machismo fragiliza todo mundo (Entrevista com Mirian Béccheri Cortez por Luiz Felipe Stevanim). RADIS, s. p., 1 nov. 2019. Disponível em: <<https://radis.ensp.fiocruz.br/index.php/home/entrevista/o-machismo-fragiliza-todomundo >> Acessado em 22 out. 2020.

BOURDIEU, Pierre. A Dominação Masculina. Rio de Janeiro: Bertrand Brasil, 1999. BOURDIEU, Pierre. O Poder Simbólico. Lisboa: Difel, 1989.

BUTLER, Judith. Problemas de gênero: feminismo e subversão da identidade. Tradução de Renato Aguiar. Rio de janeiro: Civilização Brasileira, 2003. 
CARNEIRO, Terezinha Féres. Identidade Masculina e o Exercício da Paternidade. In: FERES-CARNEIRO, T. (Org). Casal e Família: entre a tradição e a transformação. Rio de Janeiro, NAU, 1999.

CONNEL, Robert W. Masculinities. Berkeley: University of California Press, 1995.

CONNEL, Robert W.; MESSERSCHMIDT, James W. Masculinidade hegemônica: repensando o conceito. Estudos Feministas, v. 21, n. 1, p. 241-282, janeiroabril/2013.

FOUCAULT, Michel. História da sexualidade. Vol. 1. A vontade de saber. 2. ed. Rio de Janeiro: Graal, 1988.

GOLDENBERG, Mirian. Ser Homem, Ser Mulher. dentro e fora do casamento. Rio Janeiro: Revan, 1991.

KIMMEL, Michael. A Produção Simultânea de Masculinidades Hegemônicas e Subalternas. Horizontes Antropológicos, n. 9, p.103-117, 1998.

LEANDRO FERREIRA, Maria Cristina. Glossário de termos do discurso. Porto Alegre: Instituto de Letras da UFRGS, 2001.

LOURO, Guacira Lopes. O corpo educado. Pedagogias da sexualidade. Belo Horizonte: Autêntica, 2000.

LOURO, Guacira Lopes. Um corpo estranho: ensaios sobre sexualidade e teoria queer. Belo Horizonte: Autêntica, 2004.

MEYER, Dagmar Estermann. Teorias e políticas de gênero: fragmentos de história e desafios atuais. Revista Brasileira de Enfermagem, v. 57, n. 1, p. 13-18, jan./fev. 2004.

ORLANDI, Eni Puccinelli. Discurso e Leitura. 5. ed. São Paulo: Unicamp, 2000.

ORLANDI, Eni Puccinelli. Análise de Discurso: princípios e procedimentos. São Paulo: Pontes, 2001.

ORLANDI, Eni Puccinelli. O inteligível, o interpretável, e o compreensível. In: ZILBERMAN, Regina; SILVA, Ezequiel Theodoro da. Leitura perspectivas interdisciplinares. 5 ed. São Paulo: Ática, 2005.

PÊCHEUX, Michel. A análise de discurso: três épocas. In: GADET, Françoise \& HAK, Tony. Por uma análise automática do discurso: uma introdução à obra de Michel Pêcheux. (Trad. Bethânia S. Mariani (et al.). 2.ed. São Paulo: editora da UNICAMP, 1997.

SCOTT, Joan. Gênero: uma categoria útil de análise histórica. Educação e Realidade, v. 20, n. 2, p. 71-99, 1995.

SILVEIRA, Éderson Luís. A dissolução da identidade em corpos complexos: Para além do binarismo masculino/feminino. Temporalidades, v. 7, p. 148-175, 2015.

SILVEIRA, Éderson Luís. Para uma vida não fascista: notas sobre o engodo da sexualidade universal. Água Viva (UNB), v. 4, p. 1-15, 2019. 
SILVEIRA, Éderson Luís; BATISTA, Anísio Pereira. Ney Matogrosso entre Butler e Foucault: sobre sujeitos e subversões de identidades. Revista X, v. 14, p. 240-255, 2019. 